\title{
Important Steps to Skillful Mentoring of New Faculty: Avoiding the Pitfalls
}

\author{
Virendra K. Varma, Tina Varma \\ Missouri Western State College / Northwest Missouri State University
}

\begin{abstract}
There is a high rate of turn-over of new faculty members at colleges and universities. Many new faculty members elect to leave their current institutions and join new ones only after a year or two of service. Research shows a lack of support and mentoring as major causes of turn-over of new faculty members at institutions of higher education. Turn-over of new faculty is costly to institutions due to costs associated with the recruitment processes, and other investments made by the institutions in professional training and development of new faculty. The initial faculty support system offered to new faculty through skillful mentoring proves beneficial to both the new faculty and the institution. Mentoring involves a mosaic of services of several experienced faculty and the department chair. This paper addresses the important steps in establishing a structured mentoring program for new faculty; it keys in on the needs of new faculty and highlights the contributions that the senior faculty and the department chair can make to create mentoring relationships that foster collegiality among the junior and senior faculty and enhance retention rates of new faculty members. This paper is also based on the authors' own experiences, experiences of several others, and student expectations of new faculty members. A set of recommendations are made on what to include, and what pitfalls to avoid for instituting a successful and effective mentoring program for new faculty members at institutions of higher education.

Introduction

Mentoring college teachers is no more complex than mentoring new professionals in industry. The survival of new 'hires' depends largely on two things: 1) the individual's own constitution and strengths, and 2) the support system of the organization for the new hires. Many institutions of higher education provide some form of mentoring to new faculty. Mentoring programs for college and university teachers can range from totally informal to highly structured programs. Informal mentoring programs which allow new faculty to engage in self-selecting of mentors tend to be less successful compared to formal and structured programs where the institutions provide well-supported and well-funded mentoring programs. Whatever the shape and form of the mentoring program, the ultimate test lies in how well the new faculty adjust to the new culture of the institution, and become a part of the institution.

The loss of new faculty is demoralizing to departments, and to the institution as a whole. The retention of good and promising faculty is just as important as is their recruitment. Recruitment processes are expensive and time-consuming. The return of investments made by the institutions in the training and professional development activities of new faculty amounts literally to nothing if the newly-hired faculty choose not to stay after their initial period of adjustment. This
\end{abstract}

"Proceedings of the 2001 American Society for Engineering Education Annual Conference \& Exposition Copyright 을 2001, American Society for Engineering Education" 
paper addresses the proactive steps that institutions can take to retain faculty by offering a reasonably structured mentoring program. Frank Perna, et $\mathrm{al}^{1}$ and Merle Waxman ${ }^{2}$ point to important principles of viable and successful faculty mentoring programs at institutions of higher education. Some of these principles and considerations are included in the following arguments for establishing structured mentoring programs.

Essentials of Mentoring Programs

Some institutions report any where from five to ten percent of new faculty turn-over in the first two-years of their employment. ${ }^{3}$ These numbers compared to an average annual turnover in all U.S. industries of 15 percent, though may appear small, are a concern to institutions in the overall context of faculty recruitment and faculty retention. Mentoring programs are seen as a positive step towards faculty development and faculty retention by university administrators if the programs are properly administered. The design of mentoring programs should consider the following:

- Establish the purpose of the mentoring program, and define it in clear terms to participating faculty (old and new faculty).

- Seek input from senior faculty and department chairs for overall design layout of the mentoring program.

- Address both psychosocial and career development objectives of the mentoring program. It must be noted that the mentoring programs that focus solely on career development are less effective.

- Teaching is an isolated job. Collegiality helps faculty growth in several psychosocial areas. Mentoring should not always be same gender, nor should it always lend itself to same departmental pairings. Cross-departmental pairings, according to some programs, are more effective than intra-departmental programs.

- A structured mentoring program, while allowing for some flexibility to allow individual needs, is more effective than an informal program.

- Do not mandate new faculty to join the institution's mentoring program. Participation by new faculty should be voluntary.

- A mentoring program should provide a mosaic of mentoring services whereby new faculty have more than one mentor to interact with, and learn from. Mentoring programs that provide for a variety of role models to be accessible to new faculty tend to be more successful.

- Above all, mentors need to be trained too. Institutions should develop mentoring programs that have campus-wide support from both junior and senior faculty including department chairs.

\section{Facilitating Transition of New Faculty}

Soon after the new faculty arrive on campus, they find themselves immersed in teaching. Constructing course syllabi, writing quizzes, tests, etc., takes a great deal of time. Activities such as, designing project assignments, advising students, and serving on departmental and institutional committees run on a parallel course and can be a major cause of tension for the new 
faculty. It is at such critical times that new faculty members need mentors to help them navigate through unforgiving situations.

\section{Department Chair as Mentor}

The first and the most recognizable mentor in the department is the department chair. The department chair, however, is not always the best mentor because some new faculty may initially find working with the department chair somewhat uncomfortable and intimidating. All new faculty have basically the same questions about the job when they first start. To make the transition easier, the department chair should assign a junior or a senior faculty member from the department to serve as a mentor to the new faculty member. The new faculty member should feel at home in the department, and ask questions without being tied to any one single person in the department. It is also very important to have access to several other mentors on campus. In a structured mentoring program which is outlined below, new faculty are introduced to several mentors on campus in a planned meeting. Such a meeting sets the stage for networking with other faculty members on campus.

\section{Establishing a Structured Mentoring Program}

Depending upon the organizational structure of the institution, a mentoring program can be run by several different groups on campus. It can be run by the faculty senate, or more easily could be housed in the office of academic affairs. A branch of the academic affairs office can supervise the operation of the mentoring program. The following are the steps to manage a successful mentoring program.

a. Find an appropriate home for the program.

b. Appoint someone to administer the program.

c. Establish a budget for the program. The mentoring programs arrange workshops, invite speakers, and therefore are to be appropriately funded.

d. The director of the program sets up an initial mentors meeting every fall semester, and invites some 'old' new faculty (with a year or two experience), some junior and senior faculty, and some department chairs. In this introductory meeting, basics of mentoring and needs of new faculty are discussed.

e. The director of the program offers several luncheon-type workshops throughout the course of the fall and spring semesters, and a variety of topics are discussed. All these workshops are voluntary and nobody is obligated to attend. The director of the program does a lot of pre-planning to make these meetings meaningful and successful.

f. Some of the workshop topics that new faculty find interesting are:

1. Surviving: The First Six Weeks of Teaching

2. Using College/University Support Services to Make Your Teaching Life Easier

3. New Faculty Stresses

4. The Basics of Copyright

5. How to Get a Merit Raise

Ultimately, the mentoring program is only as successful as the effort and energy put into it by the director of the program and the participating faculty. 
Career Development Aspect of the Mentoring Program

In addition to psychosocial aspect of mentoring programs, one of the major objectives of a mentoring program is to enable new faculty to develop professionally and to improve their teaching and instructional methods. Technologically-relevant seminars and workshops, such as, "Creating an Effective Course Syllabus," or "Entering the Realm of the Smart Classroom," help new faculty work smarter, not harder, and thus adopt better and more productive teaching behaviors. The ultimate beneficiaries of successful mentoring programs for new faculty are the students. Students evaluate teaching; as such, student expectations of new faculty must be considered in evaluating the success of mentoring programs.

\section{What Students Expect of New Faculty}

In a recent survey ${ }^{4}$ of students and faculty, results indicated that both faculty and students considered effective teachers to be good communicators, knowledgeable, approachable, fair evaluators, and respectful of students. Faculty, however, gave higher ratings to being wellprepared, challenging, and promoting critical thinking. Students rated being creative/interesting, having realistic expectations, and being sensitive to student needs of greater importance. The perceptions of both groups were an important tool in identifying the attributes and behaviors that distinguish teachers that would be considered outstanding. This kind of information needs to be shared with new faculty early on in their careers so that they are aware of the student expectations. This is very easily accomplished through structured mentoring programs via luncheon seminars, and breakfast meetings.

\section{What Pitfalls to Avoid}

Too often new faculty may have trouble adjusting to teaching to match the knowledge base of students. New faculty may also lack skills in test construction. They may be equally uncomfortable with student evaluations in their first year of teaching. It should be pointed out that they may be unaware that they are not the only ones with these problems. New faculty are unfamiliar with departmental procedures and college policies. They need nuts and bolts information specific to their teaching and professional development. Without the help of mentors, they can remain unaware of several departmental and university-wide resources that can enable them to perform their jobs better, and with less stress. Avoid asking new faculty how they are doing with students and teaching too often. Also, mentors must refrain from being negative, and injecting their own personal biases in matters related to college policies and procedures. The mentor's job is to ease the transition, and to help the new faculty member succeed. Whenever possible, criticism should be avoided, and positive efforts appreciated. A good mentor can surely help the new professor get organized. ${ }^{5}$

\section{Conclusion}

At many institutions, mentoring is provided by the department chair, and/or by another faculty member in the department. It is also voluntary in practice. The department chair is in the best position to select and assign the right mentor to a new faculty member. The department chair also has an important role of developing new faculty into outstanding teachers and scholars. 
However, new faculty may feel intimidated by, and less comfortable working with the department chair. Therefore, new faculty members should be exposed to structured mentoring programs where individuals have freedom to develop and create a mosaic of mentoring relationships that best meet their needs. New faculty should have more than one mentor, and utilize the expertise of several faculty including the department chairs, to guide their progression. Mentoring works best when it is voluntary, and gives best results when there is willingness on the part of new faculty. The philosophy behind mentoring can be summarized in one sentence: Mentoring cannot hurt but only help a new faculty member succeed.

Bibliography

1. Perna, Frank M., et al. "Mentoring and Career Development Among University Faculty." Boston University Journal of Education. 1995, 177.2: 31-45.

2. Waxman, Merle. "Mentoring, Role Modeling, and the Career Development of Junior Science Faculty: A Look at the Yale University School of Medicine Experience." Journal of College Science Teaching. November 1992: 124-127.

3. Personal Communications with several Higher Education institutions.

4. A Survey of Students and Faculty on Effective Teachers. Missouri Western State College, Spring 2000.

5. Bensimon, Estela M., et al. "The Department Chair's Role in Developing New Faculty into Teachers and Scholars.” Anker Publishing Company, Inc., Bolton, MA.

\section{VIRENDRA K. VARMA}

Virendra K. Varma, Ph.D., P.E., F. ASCE, is currently professor of construction, and an ex-chair of the Department of Engineering Technology at Missouri Western State College. He has served as a mentor to several faculty on campus including faculty in his own department. He has over 25 years of industrial experience in highly responsible positions ranging from a project manager to a partner in an engineering company.

\section{TINA VARMA}

Tina Varma holds a B.S. degree in Biology with a minor in Chemistry, and a B.S.E. degree with a Science concentration from Missouri Western State College. She is currently pursuing graduate studies at Northwest Missouri State University. 